\title{
A educação na mudança social: lugar central, lugar secundário e lugar nenhum
}

\section{Education in social change: central place, secondary place and nowhere}

\author{
Elie Ghanem ${ }^{1}$
}

\begin{abstract}
RESUMO
Este artigo traz exemplos que sustentam a hipótese de que há uma discrepância entre o sentido geral atribuído à educação pelos enfoques sociológicos e aquele que é conferido por autoridades públicas e profissionais de organizações escolares. O sentido que tais autoridades e profissionais atribuem à educação coincide consideravelmente com as noções mais recorrentes na opinião pública, que frequentemente localiza a educação em posição central como fator de mudança social. $\mathrm{O}$ argumento foi elaborado para situar uma pesquisa sobre mudança educacional no Brasil, apoiada pela Fundação de Amparo à Pesquisa do Estado de São Paulo (FAPESP) em 2004-2005. A pesquisa dedicou-se a reportar as características das ações de reforma educacional nos anos 1990, confrontando-as com iniciativas circunscritas, abarcadas pela denominação de inovação educacional.
\end{abstract}

Palavras-chave: educação; mudança social.

\begin{abstract}
This article presents some examples to support the hypothesis which claims that seems to exist a discrepancy between the general meaning attributed to education by sociological approaches and those adopted by public authorities and school organization professionals. Those authorities and professionals
\end{abstract}

1 Professor de sociologia da educação, da Faculdade de Educação da Universidade de São Paulo (USP), Brasil. E-mail: elie@usp.br 
and the current notions in public opinion are considerably coincident: indeed, they often localize education in a central place as a social change factor, sometimes as an exclusive factor. Our argument was elaborated aiming to situate a research about educational change in Brazil, supported by Fapesp in 2004-2005. That research reported the educational reform characteristics from 1990 to 2000 and it compared them with circumscribed initiatives included under the expression of educational innovation.

Keywords: education; social change.

As linhas que aqui se apresentam foram esboçadas para situar uma pesquisa sobre mudança educacional no Brasil, apoiada pela Fapesp em 2004-2005. Tal pesquisa dedicou-se a reportar as características das ações de reforma educacional nos anos 1990, confrontando-as com iniciativas circunscritas, abarcadas pela denominação de inovação educacional. Este texto consiste em uma ilustração da hipótese de que há uma discrepância entre o sentido geral atribuído à educação pelos enfoques sociológicos e aquele que é conferido por autoridades públicas e profissionais de organizações escolares. O sentido que tais autoridades e profissionais atribuem à educação, de resto, coincide consideravelmente com as noções mais recorrentes na opinião pública, que, em geral, localiza a educação em posição central como fator de mudança social. Recente declaração do ministro da educação brasileiro assim corrobora:

Acredito que a Educação vai virar um valor social quando mais gente - não importa a área de atuação, empresário, sindicalista, intelectual - perceber que é preciso melhorar a qualidade do ensino e que esse engajamento tem impacto sobretudo na vida das famílias humildes. [...] Infelizmente, essa é a realidade do país, mas devemos continuar lutando para fazer com que a Educação assuma esse papel fundamental que tem para mudar a realidade da população. (HADDAD, 2009).

Um dirigente do Conselho Nacional de Secretários de Educação afirmou, na mesma perspectiva: "Educação, para mim, significa mudança. Significa a possibilidade de transformar o Brasil em um país melhor" (RAMOS, 2009). Com uma proposição socialista, a CNTE-Confederação Nacional dos Trabalhadores em Educação, representação sindical mais abrangente do magistério brasileiro, indica: 
Esta educação, de caráter multicultural, consubstanciada nas propostas difundidas pela CNTE, só adquire sentido se articulada necessariamente a um projeto social transformador da sociedade atual, que coloque como centro a emancipação das classes populares e sua luta por um futuro de igualdade, progresso e justiça social e numa sociedade socialista. (CONGRESSO NACIONAL DA CNTE, 2008, p. 15).

Para a opinião pública geral, também é central a posição da educação quanto ao desenvolvimento e quanto ao nível de renda. Enquete a respeito de educação detectou que $61 \%$ dos(as) brasileiros(as) eleitores(as) com 16 anos de idade ou mais concordam totalmente que "a baixa qualidade do ensino vai prejudicar o desenvolvimento do país" e $24 \%$ concordam em parte. E $83 \%$ concordam totalmente ou em parte com a afirmação: "a renda de uma pessoa será maior quanto mais anos de educação ela tiver" (CONFEDERAÇÃO NACIONAL DA INDÚSTRIA, 2010, p. 8-9).

\section{Sociologia da mudança social}

Em cada opção teórica examinada aqui, procurou-se explicitar o lugar e importância atribuída à educação, pois os problemas desta remetem a uma preocupação de fundo com a mudança social. Considerou-se o enfoque compreensivo apresentado por Sztompka (1998), que confrontou muitas teorias da mudança social, assinalando uma substituição "de esquemas mecânicos desenvolvimentistas, que reclamam a inevitabilidade" para "a ênfase na agência humana" (SZTOMPKA, 1998, p. 15). Entre as justificativas que apresenta para a importância do estudo do tema está a de que "enriquecer o conhecimento teórico sobre a mudança é sem dúvida uma tarefa de relevância prática para a produção da mudança" (SZTOMPKA, 1998, p. 16). Para ele, o antigo "modelo sistêmico" procede do "pecado original" da sociologia: a concepção da sociedade como uma entidade sólida, que levou Comte a propor a divisão entre estática social e dinâmica social, requerendo "leis de coexistência" (para um estudo sincrônico) e as "leis de sucessão" (para um estudo diacrônico). Naquele modelo, o conceito de mudança se refere à diferença entre os vários estados sucessivos da sociedade considerando um mesmo sistema, sendo que a mudança poderia variar em intensidade ou nos componentes da estrutura, a saber: mudança na composição dos elementos fundamentais (como quantidade 
e variedade de indivíduos e suas funções); mudança na inter-relação entre estes elementos; mudança nas funções dos elementos fundamentais no sistema como um todo; mudança de limites; mudança nas relações entre subsistemas e no meio ambiente. Faz-se também uma diferenciação entre mudanças no sistema, ou parciais, e mudanças do sistema, ou globais.

Sztompka chama a atenção para o desafio de captar os macroefeitos dos microeventos e, inversamente, os microefeitos dos macroeventos. Também caracteriza as mudanças por não acontecerem isoladamente, estando ligadas em relações complexas e requerendo conceitos que lidem com esta complexidade. Daí porque Sztompka aponta a importância da noção de "processo social". Este considera a pluralidade das mudanças num mesmo sistema, com relações causais recíprocas e numa sequência temporal, noção que possibilita evidenciar relações entre microprocessos e macroprocessos. Portanto, a existência da sociedade como um objeto reificado é ilusória: "O que de fato existem são processos constantes de agrupamento e reagrupamento; existem processos de organização e reorganização, e não organizações estáveis; existem processos de estruturação, e não estruturas; formações e não formas; configurações flutuantes, e não modelos rígidos" (SZTOMPKA, 1998, p. 36).

A principal diferença do enfoque de Sztompka frente ao modelo sistêmico está em considerar que as mudanças e processos são contínuos. Mas, também, sublinha que modelos devem ser julgados pela sua eficácia, sendo compreensível o ecletismo de estudos sociológicos baseados em diferentes modelos, que lançam luzes próprias sobre a mudança social. É com este suposto que se examinam a seguir as abordagens de um conjunto de estudos.

\section{Mudança social e educação}

Admitindo-se a pertinência do enfoque de Stompka, procura-se, aqui, tanto exemplificar abordagens da mudança social em obras de variada procedência quanto, em cada uma destas, caracterizar como a educação é situada. Embora seja vasta a literatura educacional que se ocupa da mudança social, a intenção de evidenciar exemplos levou à opção por um diminuto, porém, eloquente conjunto de livros. São obras de treze autores, dos últimos 50 anos, a maior parte das quais oferece análises sociológicas, embora também haja a interpretação antropológica e a filosófica, inclusive uma particular e destacada visão pedagógica, a de Paulo Freire. Os focos se voltam para fenômenos de escala mundial, da América Latina e, ainda, especificamente ao Brasil. 


\section{Sociedades modernas e globalização}

Com uma mirada bem geral, Eisenstadt (1969) busca compreender as condições sob as quais as sociedades modernas ou em modernização desenvolvem o quadro institucional capaz de "absorver" as mudanças sociais inerentes ao processo de modernização, bem como as condições nas quais ocorrem casos de "colapso" ou "regressão" da modernização. Deste ponto de vista, mudança social seria o processo histórico de mudança para os tipos de sistema sociais, econômicos e políticos que se desenvolveram na Europa ocidental e na América do Norte entre os séculos XVII e XIX, espalhando-se, então, por outros países europeus e, nos séculos XIX e XX, pelos continentes sul-americano, asiático e africano. Neste processo, ocorreu a inserção crescente de camadas mais amplas da sociedade.

Entre as consequências da modernização, Eisenstadt (1969) nomeia os processos de desorganização e deslocamento, divisão e conflito entre grupos, movimentos de protesto e resistência às mudanças. A desordem causada pela mudança (ou modernização) abrange o campo econômico por meio da industrialização, o político (com a centralização e a democratização) e o cultural, por meio do rompimento de valores e tradições há muito estabelecidos. Os problemas daí decorrentes é que contribuiriam para o aparecimento de novos movimentos sociais, mudando de foco a todo instante, a exemplo do chamado "problema da juventude". Este, por sua vez, teria sido diretamente afetado pelo aumento da especialização ocupacional, do planejamento econômico e da burocratização na maioria dos mercados econômicos, mas também pelo estreitamento da inter-relação entre a posição ocupacional e as realizações educacionais: "A expansão contínua do sistema educacional e da economia de mercado, com suas pressões diferentes de sistemas ocupacionais, de modo geral aumentou as ligações diretas entre realizações educacionais, as oportunidades econômicas e a posição ocupacional" (EISENSTADT, 1969, p. 48). Deste ângulo de visão, as mudanças educacionais são mencionadas, mas, como coadjuvantes das demais e ainda sem a explicitação dos fatores que as geram e da especificação de seus efeitos. A noção implícita de mudança educacional é a de crescente abrangência da cobertura escolar, pouco se referindo à educação praticada no sistema educacional.

O desafio da modernização estaria na "capacidade de estabelecer uma estrutura institucional adequada para absorver problemas e exigências em contínua mutação" (EISENSTADT, 1969, p. 67). Para que se evitasse o colapso e se mantivesse um progresso contínuo de modernização, seria preciso maior flexibilidade entre os grupos sociais presentes no conjunto, principalmente no campo político. Essa flexibilidade não dependeria apenas da coesão e da abertura da sociedade a vários grupos "mas também do posicionamento dessas elites e grupos nos qua- 
dros sociais mais amplos, bem como de suas forças transformadoras internas, de transformação ideológica de valores" (EISENSTADT, 1969, p. 217).

As instituições educacionais nas sociedades modernas se desenvolveriam através do padrão de procura e oferta dos serviços educacionais, que se caracterizaram pela crescente especialização das organizações e funções educacionais, bem como pela constante unificação e inter-relação das diferentes atividades educacionais nos quadros de um sistema comum. As atividades e organizações tenderam a tornar-se mais disseminadas, com diferenciação contínua entre os níveis do sistema educacional. Mas as diferentes organizações se tornaram mais estreitamente interligadas, devido ao planejamento educacional global, ou porque uma se tornou reconhecida como canal de acesso a outra ou, ainda, porque a disputa dos mesmos recursos humanos e materiais foi crescente. Não obstante, para Eisenstadt, a educação possui um papel mais passivo do que ativo no processo de modernização, pois age para adaptar-se às mudanças e não para realizar mudanças.

Em vez de restringir-se aos processos de modernização e aos seus efeitos, Giddens (1991) tenta obter uma nova caracterização da natureza da modernidade e da ordem pós-moderna que a substituiria. Suas concepções se originam de uma "interpretação descontinuista" do desenvolvimento social moderno, pelo caráter único de alguns aspectos das instituições sociais modernas. Trata-se nomeadamente do seu extremo dinamismo e do seu escopo globalizante, cuja caracterização parte da busca das fontes da natureza dinâmica da modernidade. As três características destacadas da modernidade foram designadas como separação do tempo e do espaço, desenvolvimento dos mecanismos de desencaixe e apropriação reflexiva do conhecimento. O estado-nação e a produção capitalista sistemática teriam constituído a modernidade como um projeto ocidental, mas, as tendências globalizantes da modernidade não fariam da modernidade algo peculiarmente ocidental.

As transformações envolvidas na modernidade seriam mais profundas que a maioria dos tipos de mudança característicos dos períodos precedentes. Estabeleceram interconexões sociais que cobrem o globo e alteraram algumas das mais íntimas e pessoais características de nossa existência cotidiana. Em que pese a grande projeção e a importância da perspectiva de Giddens, esta também não apresenta qualquer caracterização da educação que sobressaia no grande espectro de transformações por ele analisado.

Ianni (1995) também examina as ideias sobre a globalização, evidenciando as condições sob as quais se forma a sociedade global e os desafios que se criam para as sociedades nacionais. Partindo da história moderna e contemporânea vistas como uma história de sistemas coloniais imperialistas, geoeconômicos e geopolíticos, com a expansão dos mercados, da industrialização, da urbanização e da ocidentalização, caracteriza a globalização como desenvolvimento do capitalismo pelo mundo, sendo as mudanças também consideradas processos de 
modernização. Em tais processos, as elites intelectuais, empresariais, militares, religiosas e outras inovam, mobilizam, organizam, dirigem, explicam e põem em prática, induzindo as massas, os grupos e as classes sociais, alfabetizando, profissionalizando, urbanizando, secularizando, modificando instituições e criando novas, revertendo expectativas e diretrizes.

A globalização em curso representaria também uma nova etapa de "desenvolvimento da raça humana", em que o avanço tecnológico encurtou os espaços, com seus instrumentos na mídia impressa e eletrônica, esses com a capacidade de navegar pelo mundo e impor determinados valores ou verdades do sistema dominante (cultura ocidental). A educação, nesse contexto, cumpriria função de manutenção do atraso social em sociedades tradicionais. Função conservadora análoga seria cumprida como instituição que passa a ser controlada pela globalização, como um instrumento para a manutenção do curso globalizante, na cultura, na babel global e no modo de pensar e agir.

Guardadas as diferenças de perspectiva e de época, o objetivo de Kilpatrick (1964) foi tratar da espécie de educação que ajustaria as novas gerações à mudança presente em diversos aspectos da vida, incluído tanto o desenvolvimento técnico e seu consequente "progresso da população e da produção", quanto "o número crescente de crimes e a geral frouxidão dos costumes, principalmente sensíveis na mocidade" (KILPATRICK, 1964, p. 13). É impressionante como esta imagem é atual, ainda mais porque a primeira edição do livro de Kilpatrick é de 1932. Como muitos outros autores, ele identifica a distinção do mundo moderno ("nossa civilização") em relação ao antigo ou medieval, essencialmente no pensamento baseado na experimentação (o desenvolvimento das ciências e de suas aplicações). As decorrências são uma nova atitude mental diante da vida, a industrialização e a democracia. A primeira é caracterizada como fé no poder do homem para pensar e provar a correção do pensamento pela experimentação: "Uma tendência geral para criticar as nossas instituições, com propensão crescente para mudá-las, quando a crítica as condene, é característica pronunciada dessa nova atitude" (KILPATRICK, 1964, p. 22). A industrialização é abordada em seus efeitos de integração crescente do indivíduo e maior dependência entre os homens, que decorreria da crescente divisão do trabalho. Processo que amplia a agregação urbana e a migração do campo para a cidade, reduzindo o valor de cada indivíduo. A democracia é vista como um movimento mais amplo que uma forma de governo, incluindo a ideia de que o indivíduo deva figurar como uma pessoa e assim ser tratado: "um esforço para fundar a sociedade num princípio moral: a cada um deve oferecer-se oportunidade de desenvolvimento e expressão individual simultânea, até o ponto máximo em que isso seja possível" (KILPATRICK, 1964, p. 28).

Duas outras tendências apresentariam exigências de largo alcance à educação: o declínio do autoritarismo e o sentimento de que as coisas mudam, quer 
queiramos, quer não. $\mathrm{O}$ autoritarismo é visto como a aceitação "incondicional da autoridade que reclama submissão a si mesma, sem outra razão senão a de sua própria existência” (KILPATRICK, 1964, p. 29).

A causa principal da mudança nas condições de vida (mudança social) é localizada no grande número e variedade de invenções práticas surgidas nos cem últimos anos. A mudança permanente, veloz e cada vez mais rápida introduziria um problema novo e extremamente grave, pois o progresso material ameaçaria exceder a capacidade social e moral de compreender novos problemas que vão surgindo. Além disto: "[...] a mocidade não aceita a moral autoritária. Precisamos, então, desenvolver um ponto de vista novo e criar um sistema educativo correspondente, que tome na devida consideração o fato da mudança sempre crescente. Do contrário, a própria civilização estará ameaçada" (KILPATRICK, 1964, p. 40).

Originalmente, a educação não apenas teria estado presa à vida, mas seria parte da vida. Um ramo da educação teria se formalizado, sobrevivendo independentemente do serviço inicial que prestava (transmissão de aspectos preferidos da cultura do grupo). Para ele, esta educação dificilmente mudou em correspondência com as demais mudanças sociais:

Três tendências gerais convergem para tornar a escola conservadora e convencional: primeiro, a inércia do próprio sistema, a tendência natural do formalismo a perpetuar-se dentro de si mesmo, por toda parte; segundo, a influência de sinais exteriores de aprendizado, a importância dada a esses sinais, o que tornou, afinal, a matéria meramente convencional; e, terceiro, a possibilidade que os "conservadores" geralmente obtêm, de usar a escola para fixar, na mocidade, opiniões e atitudes que julgam de necessidade manter, de qualquer forma. [...] Até há pouco tempo, a própria escola, resistindo à mudança, foi, em geral, um baluarte contra a mudança social. (KILPATRICK, 1964, p. 43).

Apesar de muitas adaptações ocorridas, ainda restaria muito a fazer para que as escolas se adaptassem às mudanças efetuadas na vida social e as teorias básicas de educação fossem reformadas para que contivessem em si, como elemento essencial, o reconhecimento da própria mudança, permanente, rápida $\mathrm{e}$ crescente. Reconhecimento que se daria primeiro pelo dever de preparar a nova geração a crer que pode e deve pensar por si mesma, inclusive para corrigir e rejeitar as próprias conclusões de quem educa. Não seria exato que a educação tem preparado para a vida do adulto, nem para a vida presente deste nem para o futuro desconhecido que se terá que enfrentar. Além disto, tendo os pais se 
retirado crescentemente da vida dos filhos, a escola, entre outros, precisaria superar seu papel de complemento, incumbindo-se de viver com a criança.

A educação também deveria responder ao apelo que a vida moderna faz ao pensamento baseado na experimentação, orientando melhor o ensino da ciência e aumentando a capacidade de julgar (espírito crítico). A crescente especialização da indústria colocaria exigências quanto a relacionar o trabalho com o resto do processo social, com o interesse pelo grupo social e a cooperação com ele. Uma última observação de Kilpatrick quanto às exigências que a mudança colocaria a uma educação que ajustasse as novas gerações ao caráter permanente das alterações é que, supondo ser impossível aprender aquilo que não se pratica, para aprender democracia, seria preciso praticá-la.

Com enfoque completamente distinto, o objetivo de Touraine (1994) foi desvencilhar o conceito de modernidade de sua visão predominante como razão modernizadora. Distingue, portanto, modernidade de modernização (racionalização). Embora a modernidade não possa prescindir da racionalização, também se constitui da formação de um sujeito-no-mundo, que se sente responsável perante si mesmo e perante a sociedade. A modernidade se constituiria do diálogo entre suas duas faces, a racionalização e a subjetivação.

Além de uma noção própria de mudança social, Touraine apresenta e critica as variadas imagens de sociedade e de mudança. Adverte que o apelo ao Sujeito também pode tornar-se obsessão de identidade e fechamento em comunidades. Mas, ao contrário, pode ser vontade de liberdade e aliar-se à razão como força crítica. A razão também pode identificar-se a aparelhos de gestão dos fluxos de dinheiro, de decisão e de informação, destruindo o Sujeito, ou seja, o sentido que o indivíduo procura dar aos seus atos. Inversamente, a razão pode aliar-se a movimentos sociais em defesa do Sujeito, contra recursos que se concentram segundo uma lógica de poder. O triunfo da modernidade teria sido o do desencontro da racionalização e da subjetivação (modernidade limitada). Boa parte deste processo corresponderia à afirmação e decadência de uma sociedade industrial produtora de bens materiais e à sua substituição por uma sociedade pós-industrial ou programada, cujos bens são mais culturais que econômicos. A educação estaria entre esses bens. Porém, na disputa entre racionalização e subjetivação, a educação fica dividida: em parte quer modelar o indivíduo e prepará-lo para a vida em sociedade, trabalho; de outra parte, os alunos querem uma maior preocupação com suas personalidades, uma aproximação da cultura escolar com a sua cultura jovem etc. (TOURAINE, 1994, p. 259-60). 


\section{Mudança social na América Latina e Caribe}

O processo de mudança social que as nações latino-americanas atravessavam na década de 1960 foi examinado por Adams et al. (1967) do ponto de vista da sua importância para a política externa dos EUA, cobrindo as direções gerais de transformações no Brasil, Peru, Bolívia, Guatemala e México. As transformações referidas, consideradas dramáticas, atingiam as esferas da demografia e da população, da estrutura social e da vida econômica, religiosa e política, bem como as relações internacionais. Nestas mudanças, ressaltou-se o papel da classe média, entendida como larga faixa social que vai do professor ao comerciante da cidadezinha do interior. A despeito da sua patente heterogeneidade, era o segmento de mais contato com o mundo moderno e o mais suscetível às influências modificadoras.

Quanto à educação, esta foi apontada genericamente como necessária para as mudanças, principalmente devido ao desenvolvimento do setor industrial. Mas, especialmente no caso do Brasil, ressaltou-se a expansão do sistema educacional da década de 1950, sua relação com o rápido crescimento populacional e o nível excessivamente baixo do perfil escolar da população brasileira. Colocou-se em relevo que o sistema educacional vigente não satisfazia necessidades e exigências da nossa população, sobretudo nos estados nordestinos. A grande reprovação das crianças das primeiras séries do ensino primário causava superlotação das escolas e o sistema educacional, orientado para o treinamento de uma elite relativamente pequena, não estava "sincronizado com as necessidades da sociedade brasileira em modificação" (ADAMS et al., 1967, p. 177).

Muito saliente é a concentração de Cardoso (1969) em problemas da estrutura social e política dos países subdesenvolvidos, analisados perante os centros hegemônicos capitalistas (numa ótica econômica) em sua condição de dependência. Esta vertente supôs que só se interpretariam de forma correta as mudanças sociais e políticas quando se estabelecessem os "efeitos de dominação" dos vínculos de dependência. Ressalta, porém, que a situação da América Latina não era somente determinada pela imposição externa. A influência dos "setores tradicionais", a ligação que estes mantinham com o conjunto da sociedade nacional e com as economias dominantes e também a influência dos grupos industriais e financeiros modernos redefiniam internamente e externamente os vínculos com os demais interesses econômicos e grupos sociais, assumindo caráter decisivo para as possibilidades de transformação social e de desenvolvimento econômico.

A reorganização das relações entre grupos sociais a partir da formação da sociedade industrial mostrava sinais de crescimento econômico e mudanças 
sociais, mas, devido à dependência, a América Latina utilizava tecnologia relativamente desenvolvida (sem mão de obra) deixando de criá-la em seus países e de alcançar intensidade para mudar os mercados internos. Combinava a exportação de produtos primários, a baixa dos preços, a importação de equipamentos industriais e meios financeiros de assegurar a continuidade na indústria. Paralelamente, as cidades cresciam com a exclusão socioeconômica, gerando um excedente em situação de desemprego, ao passo que o meio rural, em lenta, mas, contínua transferência para os centros urbanos, era englobado por uma industrialização excludente.

Cardoso procura superar o equívoco por ele apontado de analisar a América Latina na expectativa do desenvolvimento endógeno observado na Europa e nos Estados Unidos. A visão enganosa, abstraindo a peculiaridade do continente, supunha uma acumulação de pressões gerando mudanças parciais e futuras mudanças da sociedade como um todo. O modelo para a América Latina passar de subdesenvolvida a desenvolvida e de tradicional para moderna suporia apenas que, em geral, sistemas sociais estão em equilíbrio instável e sua transformação se dá por acúmulo de tensões de forças antagônicas. Tal embasamento teórico não permitiria que a especificidade estrutural do subdesenvolvimento viesse à luz, pois a análise da mudança social transformava o "movimento social" (significando força de negação de uma ordem em favor de outra) em "desequilíbrio entre fatores", opondo mecanicamente "obstáculos à mudança" e elementos favoráveis a esta. Este modelo, considerado funcionalista, no máximo levaria a entender a transformação como somatória de pontos de atrito que redefinem um padrão estrutural, tendo como exceção Cuba, pois a ruptura ocorreu sem continuidade entre subdesenvolvimento e desenvolvimento. A teoria de que a mudança se faz por soma de disfunções não se sustentaria, em vista da existência de disfunções que não acarretavam transformações estruturais políticas ou sociais. Além disso, quando disfunções produziam transformações econômicas, poucos aspectos na forma de organização da sociedade se alteravam sem que a relação entre desenvolvimento e subdesenvolvimento mudasse.

$\mathrm{Na}$ América Latina, a atuação dos agentes sociais de mudança e conservação teria variado pelo modo como as diferentes sociedades nacionais submeteram a sua economia ao mercado mundial. A constituição do estado nacional e dos grupos sociais se deu através da possibilidade que estes tiveram de controlar o sistema produtivo. As massas atuavam indiretamente exercendo pressão sobre a estrutura política e o sistema econômico. Grupos restritos atuavam com pressão direta sobre o Estado como peso determinante e importante. O "setor tradicional" representado pela expressão rural, por sua vez, era o divisor entre subdesenvolvimento e desenvolvimento, sendo que as massas camponesas, embora não participantes, eram fundamentais. 
O aumento populacional, do mercado e da urbanização, abalando a economia agrária e acarretando o aumento da "participação do povo na política", levou a maior frequência de expressão política e pressão das massas populares, resultando em movimentos populistas que se mostravam mais eficazes em juntar as massas, que almejavam maior participação social e política e maior oportunidade de consumo. O desenvolvimento econômico industrial constituiu "sociedades de massa" por um novo ajustamento entre as várias camadas sociais, devido à mobilização de dois fatores: participação das massas implicando a quebra da passividade com as novas perspectivas de ação política; integração de forma institucional e "legítima". A transferência da sociedade agrária para a de massas dependeu de muitos fatores relacionados ao crescimento industrial, às condições dos grupos dominantes e ao tamanho da resistência que a estrutura tradicional tem para com as massas. Se a sociedade tradicional se mostrava muito rígida e arbitrária, uma consequência foi a inversão total desse estado. Note-se que, em toda essa análise de Cardoso (1969) sobre mudança social na América Latina, não há qualquer menção a um desempenho notável da educação entre os fatores considerados e as grandes alterações.

Germani (1973), por sua vez, numa abordagem em termos de modernização que guarda muita afinidade com a de Eisenstadt, analisa as mudanças sociais ocorridas no que chamou "período de transição" da "sociedade tradicional" para a "sociedade industrial", primeiramente em um âmbito geral, posteriormente na América Latina e, ainda, especificamente, na Argentina. A proposição básica em que fundamenta sua exposição é a afirmação da unidade do mundo sociocultural e um dos aspectos primordiais da mudança sublinhados é o seu caráter assincrônico. As modificações do mundo sociocultural teriam velocidade variada (às vezes, direção variada) nos diferentes setores da sociedade, ideia que sustentaria a noção de retardamento cultural.

Germani entende que a noção de mudança supõe a de estrutura, sendo que uma modificação desta é tradução daquela. A compreensão do processo de transição, por sua vez, imporia ir além das mudanças que ocorrem em uma única dimensão, obrigando a três níveis de análise (organização social, morfologia social e psicologia social) necessários para destacar os fenômenos que podem assumir significado causal no processo de mudança. Um exemplo é o da mudança política, que, de modo geral, não produz modificações no sistema familiar de maneira direta e perceptível. Diferentemente da ocorrência de modificação no sistema educacional, que, tornando compulsória a instrução primária, produziria inevitáveis repercussões no funcionamento da família. Porém, a educação é vista por Germani mais como efeito de outros fatores de mudança. As primeiras fases das sociedades "em via de desenvolvimento" teriam afirmado a necessidade de instrução primária universal, seguindo-se a exigência de estender também de 
maneira universal o ensinamento secundário e, assim, estabelecer reformas educacionais capazes de racionalizar o sistema de recrutamento. Esses fatos teriam sido resultantes de maior participação cultural e política das classes populares, mas também se constituiriam em uma resposta à necessidade de alcançar um grande aproveitamento dos recursos humanos.

\section{Mudança social e educação no Brasil}

Analisando especialmente o papel da educação frente ao desenvolvimento ou à resistência a este, Moreira (1959) enfoca a América Latina a partir do exemplo brasileiro tendo como pano de fundo as diferenças de nível de desenvolvimento econômico das suas diversas regiões. Centra-se na educação escolar pública e em seus índices comparados a outros, nomeadamente analfabetismo e classe social, concluindo que a educação não chegava a ser um fator impeditivo ao desenvolvimento, mas, estava longe de ser um fator positivo. Para Moreira, a mudança social levaria a uma maior divisão do trabalho e consequente especialização da mão de obra. Ele monta uma espécie de ciclo, esquematicamente: a educação leva a uma mudança social (por inconformismo, por exemplo), que leva a uma consequente necessidade de especialização, que, por sua vez, reclama uma educação que solucione o problema. No entanto, a educação pública institucionalizada só poderia surtir efeito dentro de um meio que apresentasse certas condições socioeconômicas. Ou seja, para causar mudança social, é necessário certo nível de desenvolvimento como pré-requisito, por exemplo, ricos aprendem mais, ou frequentam mais a escola que os pobres. Ademais, o crescimento dos sistemas escolares não seria simultaneamente acompanhado das transformações qualitativas correspondentes às mudanças determinantes daquele crescimento. Houve até crescimento do número de escolas, mas, sem que a "mentalidade" mudasse no mesmo ritmo. Moreira também vê a educação mais como causa de conservação que de mudança social: "Será difícil uma mudança provocada pela educação, a não ser de modo indireto ou como segundo condicionante" (MOREIRA, 1959, p. 6). A escola não seria um fator de mudança por seu caráter elitista de seleção dos mais aptos.

Pela conceituação de Fernandes (1960) no estudo das relações entre mudança, evolução e desenvolvimento social no Brasil, entende-se a mudança social como uma noção genérica, abrangendo quaisquer espécies de alterações do sistema social, independente de condições particulares de tempo e de espaço. A evolução social seria uma noção mais complexa, aplicável aos processos de 
mudança progressiva. Já o desenvolvimento social teria o sentido de multiplicação de formas de interação numa determinada sociedade, acompanhando o desenvolvimento cultural, "abrangendo todos os aspectos dinâmicos de alterações da estrutura, da organização e dos mecanismos de controle de dado sistema social em um determinado período" (MOREIRA, 1959, p. 12).

Fernandes identifica uma relação direta da educação com a mudança social, afirmando que a bandeira pedagógica que se ergueu foi a da formação das elites, com interesse puramente técnico, administrativo e profissional, correspondendo a necessidades inegáveis da ordem econômica e prática. $\mathrm{O}$ único nível do ensino que atingiu parcelas variáveis das camadas populares foi o do ensino primário, embora sem ter produzido "efeitos educativos desejáveis". Porém, a escola primária não contribuíra para criar convicções definidas "concernentes à consciência de afiliação nacional e dos direitos cívicos, que poderiam servir de lastro emocional e de inspiração racional de futuros ajustamentos na vida política" (MOREIRA, 1959, p. 100). A expectativa de Fernandes em relação à educação escolar é muito elevada, de preparo "dos imaturos para se ajustarem a papéis políticos específicos em nossa sociedade, pois outras instituições, como a família ou grupos partidários não tem a preocupação de esclarecer, de educar politicamente os jovens" (MOREIRA, 1959, p. 101).

Indo além dos fatos observáveis, Fernandes defende que a educação prepare para a vida e que a escola brasileira desenvolva atividades coerentes com os ideários democráticos de personalidade e de existência social. Entendendo que o sistema educacional brasileiro não cumpria com seu papel e que o proposto até aquele momento não surtiu efeitos positivos, seria preciso novo planejamento, uma orientação diferente, pois as reformas educacionais realizadas desde os anos 1920 seguiram tendências educacionais conservantistas.

Outra faceta conservadora da educação brasileira foi iluminada por Foracchi (1965), ao abordar "o jovem e o estudante" como categoria social no intuito de compreender o seu campo de ação, tendo em vista "os estudantes universitários brasileiros". O comportamento "do jovem" foi estudado em vários aspectos: nas relações mantidas com a família, com o trabalho, com sua classe social, com sua carreira profissional, enfim, com todos os fatores que se supunha construir e afirmar sua posição política, o que influenciaria no campo de ação do "processo de transformação social".

Em tal enfoque, o processo educacional, principalmente do nível superior, remete à ideia de qualificação, requisito básico de ascensão, ratificando uma trajetória já realizada que firma uma posição social específica e privilegiada, a da pequena burguesia. Supondo a grande maioria de frequentadores do nível superior como pertencentes a esta classe, partilhando de seus interesses, numa origem social marcada pela ambiguidade, a pesquisa de Foracchi procurou as 
possibilidades de definição positiva da participação ativa do estudante, na tentativa de mudanças, em contato com um ambiente de influência politizadora, onde o campo de reflexão é maior e cobra certas ações.

A educação estabelecida como mecanismo e requisito de ascensão estaria associada a processos amplos (urbanização, secularização da cultura etc.), no impulso a movimentos individuais e grupais de transformação da situação de classe de origem. Porém, a formação universitária, em particular, menos que uma oportunidade original de ascensão na escala social, representaria uma consolidação da trajetória ascensional percorrida pela família. O desempenho da educação, portanto, foi situado como fator de consolidação da integração funcional para a parcela mais escolarizada da pequena burguesia.

Contrastando com o esforço de Foracchi, o trabalho de Freire (1979), de caráter mais prescritivo que analítico, tem o objetivo de alertar sobre a responsabilidade de profissionais de educação perante a sociedade, sobre seu compromisso em colaborar com um processo de transformação social. Neste alerta, critica as opções - principalmente as tradicionais, sendo estas de caráter ou "humano-idealista", em que a sociedade humana está acima das lutas de classe; ou "humano-tecnológico", em que a educação é apenas tratada como um conjunto de métodos - que tomam a posição de educar indivíduos à ingenuidade (a chamada educação bancária), para que olhem para a realidade como algo pronto, dado e imutável. Frente às duas opções, afirma que o homem deve ser sujeito de sua própria educação e não objeto desta. A importância conferida a este caráter de sujeito ("vocação ontológica do homem") explica também a noção de mudança social como maior "participação do povo em seu processo histórico". Porém, a educação requerida para que o homem brasileiro viesse a se "inserir criticamente no seu processo histórico" é uma aspiração, não uma constatação: a que libertaria pela conscientização, no lugar da que domestica e faz comunicados. Esta aspiração deixa supor que o caráter da educação de fato (não a pretendida) seria de abstenção ou de oposição à mudança social, qualquer que fosse a orientação que esta assumisse.

Igualmente concentrada na compreensão do Brasil a partir da desagregação da sociedade patrimonialista e da formação da sociedade urbano-industrial, outra pesquisa que gerou conhecimento de grande referência (LOPES, 1976) dedicou-se à constituição e importância do sistema industrial, bem como à consolidação do mundo urbano e de seus estilos de vida. Por essa via, procura contribuir para a caracterização das formas concretas pelas quais se deu a mudança social. Primeiro assinala o início da industrialização como subproduto do setor exportador, baseada no mercado urbano oriundo daquele setor e impulsionada pela substituição de importações, quando houve rupturas de vínculos com o mercado mundial. Surtos de industrialização se deram em concentração geográfica no 
Centro-sul, alterando a vida das populações rurais e provocando intensos deslocamentos migratórios. A estes, juntaram-se outros "efeitos de modernização" decorrentes da constituição da rede de transportes e comunicações, da extensão do sistema educacional, da difusão da legislação social e dos serviços públicos.

Um sistema de educação em massa teria se somado às migrações e meios de comunicação de massa, "filtrando" a cultura urbana pelo Brasil. A escola primária seria agente de urbanização por colocar professores portadores da cultura urbana em contato com a massa de crianças rurais. Além disso, ao alfabetizá-las e transmitir-lhes atitudes e valores urbanos, torná-las-ia mais suscetíveis de sofrer efeitos dos demais veículos de comunicação. Também aqui a educação é caracterizada como fator de adaptação complementar ao agente de mudança.

\section{Conclusão}

O breve panorama de abordagens aqui apresentado explicita algumas das principais posições ocupadas pela educação frente à mudança social: como resistência ou adaptação a uma ordem que surge de processos de mudança, como reafirmação de uma ordem antiga ou como um campo anacrônico de ideias e de práticas, inadequado a processos de mudança. Neste espectro, contudo, a educação é desconsiderada ou posta em lugar secundário. Algumas proposições se manifestam como aspiração ou prescrição, mas, nenhum dos autores do apanhado ilustrativo sumariado se remete a realidades nas quais a educação assume a condição de fator determinante, influente ou condicionante positivo da mudança social. Múltiplas modalidades de expressão do significado da educação na opinião pública permitem afirmar que esta é compatível com a ideia da educação como fator de mudança social e, particularmente, de aperfeiçoamento da vida social. Nisto, a opinião pública e, em consonância, a posição de autoridades e profissionais da educação se afastam da pesquisa social rigorosa e do pensamento sistemático, ainda quando este se incline menos à exposição de fatos que à formulação de orientações práticas.

\section{REFERÊNCIAS}

ADAMS, R. N. et al. Mudança social na América Latina. Tradução de Victor M. de Moraes. Rio de Janeiro: Zahar, 1967. 288 p.

CARDOSO, F. H. Mudanças sociais na América Latina. São Paulo: Difusão Européia do Livro, 1969. 238 p. 
CONFEDERAÇÃO NACIONAL DA INDÚSTRIA. Pesquisa CNI-Ibope: retratos da sociedade brasileira: educação (ago. 2010). Brasília: CNI, 2010. 42 p.

CONGRESSO NACIONAL DA CNTE, 3., 2008, Brasília, DF. Caderno de resoluções. Brasília: CNTE, 2008. 55 p.

EISENSTADT, S. N. Modernização: protesto e mudança: modernização de sociedades tradicionais. Tradução de José Gurjão Neto. Rio de Janeiro: Zahar, 1969. 224 p.

FERNANDES, F. Mudanças sociais no Brasil: aspectos do desenvolvimento da sociedade brasileira. São Paulo: Difusão Européia do Livro, 1960. 401 p.

FORACCHI, M. M. O estudante e a transformação da sociedade brasileira. São Paulo: Nacional, 1965. $365 \mathrm{p}$.

FREIRE, P. Educação e mudança. 26. ed. Rio de Janeiro: Paz e Terra, 1979. 79 p.

GERMANI, G. Política e sociedade numa época de transição: da sociedade tradicional à sociedade de massas. Tradução de Eurico de Lima Figueiredo e José Jeremias de Oliveira Filho. São Paulo: Mestre Jou, 1973. 309 p.

GIDDENS, A. As conseqüencias da modernidade. Tradução de Raul Fiker. São Paulo: Unesp, 1991. 177 p.

HADDAD, F. Entrevista Fernando Haddad. 2009. Disponível em: < http://educarparacrescer.abril.com.br/politica-publica/entrevista-fernando-haddad-428792.shtml $>$. Acesso em: 29/9/2010.

IANNI, O. Teorias da globalização. Rio de Janeiro: Civilização Brasileira, 1995. 225 p.

KILPATRICK, W. H. Educação para uma civilização em mudança. 4. ed. Tradução de Noemy S. Rudolfer. São Paulo: Melhoramentos, 1964. 92 p.

LOPES, J. R. B. Desenvolvimento e mudança social: formação da sociedade urbano-industrial no Brasil. 3. ed. São Paulo: Nacional, 1976. 211 p.

MOREIRA, J. R. Hipóteses e diretrizes para o estudo das resistências à mudança social, tendo em vista a educação e a instrução pública como condições ou fatores. Curitiba: Associação de Estudos Pedagógicos, 1959. 27 p.

RAMOS, M. N. Educar para crescer: membros do conselho consultivo. 2009. Disponível em: <http://educarparacrescer.abril.com.br/institucional/iniciativa.shtml?pag=43>. Acesso em: 29/9/2010.

STOMPKA, P. A sociologia da mudança social. Tradução de Pedro Joergensen Jr. Rio de Janeiro: Civilização Brasileira, 1998. 568p.

TOURAINE, A. Crítica da modernidade. Tradução de Elia Ferreira Edel. 3. ed. Petrópolis: Vozes, 1994. $431 \mathrm{p}$.

Texto recebido em 11 de janeiro de 2010 .

Texto aprovado em 25 de maio de 2011. 
